\title{
SOCIAL FACTORS, SOCIAL SUPPORT AND CONDOM USE BEHAVIOR AMONG YOUNG URBAN SLUM INHABITANTS IN SOUTHWEST NIGERIA
}

\author{
Adebola A. Adedimeji ${ }^{1}$, Nathan J. Heard ${ }^{2}$, Oluwole Odutolu ${ }^{3}$ and Femi O. Omololu ${ }^{4}$
}

\begin{abstract}
Objectives: Despite widespread knowledge that condoms offer protection against STIs/HIV when used correctly and consistently, many young people do not regularly use condoms, thus leading to new sexually transmitted infections, including HIV and AIDS. This study explored condom use behaviour, specifically the extent to which beliefs, self efficacy, risk perception and perceived social support act as predictors of use or non-use of condoms among sexually active young people aged 15-24 years.

Methods: Data was obtained from sexually active 448 boys and 338 girls, who were selected through multistage sampling techniques. Analysis of data, which was done with EPI Info and SPSS version 12, focused on predictors of condom use or non-use.

Result: Generally, there is widespread knowledge and low levels of condoms use, despite high levels of risky sexual behaviour. Although, half of boys and one third of girls report ever using condoms, a considerably lower proportion of male and female adolescents regularly use condoms. Logistic regression models show that among girls, those who perceived social support from peers and non-parental figures were more likely to use condoms while among boys, earning an income, high risk perception and self efficacy were associated with higher odds of condom use.

Conclusions: Programs aiming to increase condom use among young people need to address these factors through community-based strategies.
\end{abstract}

Key words: $\quad$ Condoms; young people; urban slum residence; social support; Nigeria.

\section{Background}

Successive UNAIDS report on the status of the global AIDS epidemic have shown that adolescents, and especially girls, still account for most cases of new HIV/AIDS infections in sub-Saharan Africa despite huge investments to address their sexual and reproductive health needs. Many Nigerian adolescents, like their counterparts elsewhere, engage in high-risk sexual behaviour (1-7) thus, consequences such as unwanted teenage pregnancy, unsafe abortion, high prevalence of HIV and other sexually transmitted infections (STIs) (3) are rife.

The prevalence of HIV suggests that Nigeria may become one of the worst affected countries in subSaharan Africa. Within a period of 10 years, sentinel survey data (1991-2001) indicate that HIV prevalence rates increased from $1.8 \%$ in 1991 to $5.8 \%$ in 2001 (3), thus making Nigeria one of the countries with the highest absolute numbers of infected people in the world. Results of the 2003 sentinel survey data (8) indicate that more than 5 million Nigerians are infected with HIV and in the absence of a cure, hopes for reducing the spread of the infection continue to rest on propositions for abstinence and adoption of protective behaviour among those who are sexually active.

Concern about young people's vulnerability to new HIV infections has led to a deluge of youth-oriented reproductive health programs focusing on protective behaviour, especially condom promotion (9), as a means of stemming the tide of infection. The theoretical assumptions for these programs (health belief model, social cognitive theory, social inoculation theory, AIDS Risk Reduction Model and Stages of Change Model) is

Corresponding to: Adebola A. Adedimeji, Centre for Global Health, 3-4 Foster Place, University of Dublin Trinity College, Dublin 2, Ireland, Tel: +353-1-8962764, Fax: +353-1-677-4956, Email: adebola.adedimeji@tcd.ie

${ }^{1}$ University of Dublin, Trinity College, ${ }^{2}$ Harvard School of Public Health, Boston, United States, ${ }^{3}$ Harvard AIDS Prevention Initiative in Nigeria, ${ }^{4}$ University of Ibadan, Ibadan, Nigeria that the adoption of protective behaviour is based on an individual's perceptions of their susceptibility to infections and the benefits of behaviour change. People are seen as rational beings who logically consider various courses of action before acting once they have adequate information and see the benefits of change. Some studies $(10,11)$, however, contend that applying such theories in the African setting may not be that simple considering that in many societies, peoples' capacity to initiate health enhancing behaviour are mediated by power relations, poverty, gender inequality and socialization processes that are beyond the control of individuals. In addition, many existing program strategies do not account for important socio-economic, educational, biological and cultural differences among adolescents, especially those that have implications for their abilities to avoid risky sexual relationships, adopt and sustain protective behaviors and access reproductive health services.

The situation is graver for adolescents who live in slum dwellings and whose opportunities to safeguard their sexual health are particularly limited. This is in view of conditions of extreme deprivation and poverty in such areas, which compel some young people to engage in risky sexual behaviour for economic survival. Brockerhoff and Brennan (12), report that in general the urban poor are even more disadvantaged in terms of health and education than their rural counterparts. The research of Zulu and colleagues (13) similarly indicates that the health disadvantages of the urban poor extends to sexual health, with women who live in slums beginning sexual intercourse earlier and having more sexual partners than their non-slum counterparts.

In the absence of a vaccine or other measures to prevent the spread of HIV, condoms have proven to be highly effective in curtailing the transmission of HIV (1417). When used correctly and consistently, male condoms can provide as much as a $94 \%$ reduction in risk of HIV transmission (18). Condoms have therefore been promoted as a major public health strategy to combat unwanted pregnancies and the rising rates of STIs, including HIV/AIDS. To derive maximum benefit, condoms must be used correctly and consistently; 
however consistent use requires long-term commitment and a reliable distribution network that provides condoms even to the poorest groups (15).

Available literature indicates a widespread knowledge of condoms among Nigerian adolescents (7, 19-24), but knowledge alone does not determine use. These studies show that despite universal awareness and knowledge that consistent use of condoms largely protects against infection with STIs and HIV, the level of condom use is relatively low among sexually active adolescents. The 2003 Nigerian Demographic and Health Survey data show that among men aged 15-19 and 20-24 years, the proportion reporting ever using condoms was $9.8 \%$ and $30 \%$, while among women in the same age groups, the proportion was $6.5 \%$ and $14.8 \%$ respectively.

Studies (25-27) reported a high level of inconsistency in condom use among current users despite intense condom promotion, and some studies (28-31) have noted that inconsistent use of condoms increases the risk for HIV infection. As Hearst and Chen (27) suggested, this is probably why huge increases in condom promotion and distribution have not resulted in corresponding adoption of safe behaviour nor significant decreases in the prevalence of HIV in sub-Saharan African countries worst hit by the epidemic. This scenario underscores the need to understand the pathways and dynamics of condom use or non-use among adolescents. Armed with such knowledge, policymakers can plan and execute relevant and context specific strategies to encourage condom use and scale down risky behaviour.

Existing research also suggests that the social environment of adolescents is an influential factor in the decision to use condoms $(21,32-36)$. Individuals form their own views in consonance with or in opposition to the dominant norms of their peers, family and society. Young people tend to feel more comfortable discussing sexuality with their peers, though the information circulating among adolescents might not be accurate. Barker and colleagues (38) reports on prevalent misconceptions among adolescents about the efficacy and side effects of condoms. Still, peer support for condom use may exert a powerful influence on individuals. In addition, other studies (39) found that parental support was a significant predictor of condom use among adolescents in urban Cameroon, especially for young women. Social support is therefore critical, given the strong influences that the social environment exerts on adolescent sexuality especially in developing societies (40). The relative influence of these social forces on condom use is, however, unknown.

This study uses survey data to examine the effect of social factors and social support on condom use among economically disadvantaged adolescents living in urban slums in Ibadan, Nigeria. It examined the extent to which beliefs and self efficacy about condoms, risk perception and perceived social support act as predictors of use or non-use of condoms among those sexually active young people aged 15-24 years. The data is derived from a large-scale project that investigated the knowledge of STIs/HIV/AIDS, perception of risks and preventive behaviour among slum dwellers in Ibadan metropolis, Nigeria.

\section{Study setting}

Ibadan municipality, the study setting is one of the largest indigenous metropolitan areas in sub-Saharan Africa with an estimated population of about 2 million inhabitants made up of people from different parts of Nigeria and other parts of the world. The city, located on a major transport route to the northern parts of Nigeria, is the largest of contemporary traditional Yoruba towns.

\section{Data and Methods}

\section{Sampling}

The survey gathered information from a sample of young people aged 15-24 living in 8 slum communities in the Northeast and Southeast local government areas of Ibadan metropolis and asked a range of questions about reproductive health issues including knowledge of STIs/HIV/AIDS, risk perceptions and preventive behaviour.

Participants were selected through multi-stage sampling techniques. Stage one involved a purposive selection of 2 Local Government Authorities (LGAs) within which there was a high density of slum communities. Stage two involved a mapping exercise to generate a list of communities in the 2 LGAs. This mapping yielded a list of 72 communities from which 8 communities: Ita-Ege, Esu-Awele, Isale-Ijebu, Odinjo, Agugu, Ode-Aje, Irefin and Aworawo were selected by systematic sampling. Systematic sampling techniques were further applied to select 5 enumeration areas (EAs) from each selected community. With this procedure, a total of 40 enumeration areas were selected. Forty respondents equally divided between males and females and age groups 15-19 and 20-24 years were selected from each EA making a total of 200 respondents from each community. Individual participants were selected by simple random techniques from a list of households containing at least one eligible respondent.

\section{Instrument}

A self administered questionnaire, containing one hundred and fourteen items on sexual experience, reproductive health knowledge, knowledge of STIs/HIV/AIDS, condom knowledge, attitude and use, risk perception and health seeking behaviour was used in obtaining information from subjects. The questionnaire was pre-tested on 30 adolescents within the selected age range to ensure that it was clear, unambiguous and acceptable. Study participants were briefed on the objectives of the study and informed consent was obtained before interviews commenced. 


\section{Interviews}

Interviews were conducted over a 4-month period. The interviews were conducted by same sex interviewers of the same age as respondents or slightly older. All the interviewers participated in a three-day training workshop prior to data collection. The field team consisted of 32 interviewers (4 per community, consisting of two males and two females) and 8 supervisors. All interviews were conducted in Yoruba, the language commonly spoken in the area. Most interviews lasted between 40 and 55 minutes with an average duration of 45 minutes. The community leaders, parents and young people in the communities were briefed on the objectives of the study and their permission sought before the field work commenced. Informed consent was obtained both from the head of the household and from individual respondents before instruments were administered.

\section{Methods}

Data were entered and cleaned using EPI INFO version 6. Analysis was performed using SPSS version 12. The data used in this paper focused on the information obtained from 786 (448 boys and 338 girls) sexually active unmarried respondents reporting sexual activity in the three months before the interview. Both bivariate and multivariate analyses examined the factors that predict ever use and likely use of condoms. Bivariate analysis examined respondents' background characteristics and general attitudes/beliefs about condoms. The variables used include respondent's sex, religion, current school status, highest educational attainment, income status and indicators of self efficacy and perceived social support measured by responses obtained to questions on peer, parental and community support for adolescent who use condoms.

Measuring condom use, the dependent variable used in the multivariate analysis, is fraught with a lot of problems including self-report bias, re-call bias, participation bias, reliability problems, social desirability responses, and memory error. To minimize these problems, positive responses from three variables of 'ever use', 'use within the last 3 months' and 'use during the last sexual intercourse' were combined to identify participants who were more likely to be consistent in using condoms. The multivariate analysis, using logistic regression models, examined demographic, economic, attitudinal and perceived social support indicators that influence condom use among those who are more likely to be consistent users. Those who reported positively on all three variables of 'ever use', 'use within the last 3 months before the survey' and 'use during the last sexual encounter' (defined as 'likely users') were coded as ' 1 ' and ' 0 ' if otherwise. The resulting coefficients represent the effect of a one-unit change in the explanatory variables on the indicator of likely condom use. Odds ratios larger than one indicate a greater likelihood of use than for the reference category. The logistic regression function has the form $1 \mathrm{n}(\mathrm{p} / \mathrm{q})=\mathrm{B}_{0}+\mathrm{B}_{1} \mathrm{X}_{1}+.+\mathrm{B}_{\mathrm{i}} \mathrm{X}_{\mathrm{i}}$, where $\mathrm{p}$ is the probability of using condoms; $q$ (or $1-p)$ is the probability of not using condoms; $\mathrm{B}_{0}, \mathrm{~B}_{1} \mathrm{~B}_{\mathrm{i}}$ are regression co-efficient; and $\mathrm{X}_{1}, \mathrm{X}_{2} \ldots \ldots \mathrm{X}_{\mathrm{i}}$ are factors. The exponent of the regression coefficients of the parameter estimated would give the odds ratios in the logistic regression models. All analyses are estimated separately for male and female respondents to demonstrate important differences that may exist between the sexes.

\section{Study Limitations}

Some limitations were identified in relation to the study. The results reported in this paper are based on selfreported information, which is subject to reporting errors and bias. The type of data collection methods used in this case (personal interviews) may have contributed to such errors. For example, several studies have demonstrated that surveys conducted using personal interviews, computer assisted self-interviews (CASI) and audiocomputer assisted self-interview (audio-CASI) yield different estimates of levels of sensitive behaviors, although, which of these data collection approaches is most accurate remains to be determined (41-43,). Nevertheless, there is also evidence that self-reported sexual behaviour data, though subject to reporting bias, can provide useful data that may help to design targeted intervention, as demonstrated by the often substantial and significant associations between reported risk and HIV infection studies from various African settings (44-46).

Another limitation is related to measuring condom use, which is the dependent variable in the study. Some studies (47-49) have identified several problems associated with measuring self reported condom use, including self-report bias, participation bias, test-retest reliability problems, social desirability responses, and memory error. Moreover, premarital sex and condom use is a sensitive topic that many adolescents are reluctant to talk about. It is likely therefore that these limitations may also have contributed to the bias in reported condom behaviour.

\section{Results}

\section{Respondents' characteristics}

Table 1 shows the characteristics of the working sample, which is restricted to unmarried males and females across 2 age groups, 15-19 and 20-24 years who reported sexual activity in the three months before the survey. As observed from the table, older adolescents outnumber younger ones and males outnumber females. Although, Nigeria is a multi-religious society, two-thirds of participants are Muslims and indication of the large number of Muslims residing in the study areas. Information relating to educational status shows that males reported higher educational attainment than females in both age groups. Due to the economic situation in Nigeria, many adolescents are involved in economic activities to generate income for themselves or to supplement their family income. Older (20-24) male and female participants make up the majority of those who reported engaging in an income generating activity.

Across gender and age categories, less than $50 \%$ of participants reported ever using condoms. More males (48.6\% among $15-19$ year olds and $49.4 \%$ among $20-24$ 
year olds) and fewer females (32.6\% among those aged $15-19$ and $39.4 \%$ among those aged $20-24$ ) reported ever using condoms. Among those reporting ever using condoms, $61.7 \%$ of males aged $15-19$ and $62.1 \%$ of males aged 20-24 did not use a condom during the last sexual activity. The proportion among females is $64.8 \%$ among those aged 15-19 and 70.1\% among those aged 20-24 years. Risky sexual activity was common among participants with $48 \%$ reporting multiple sexual partners in the last 30 days preceding the survey. Among males, about $45 \%$ of those aged $15-19$ and half of those aged 20 24 reported sexual activity with 2 or more partners during this period. The proportions among females were $14.7 \%$ of those aged 15-19 years and $10 \%$ of those aged 20 24years.

Table 1: Characteristics of sexually active respondents

\begin{tabular}{|c|c|c|c|c|}
\hline \multirow[t]{2}{*}{ Characteristics } & \multicolumn{2}{|c|}{ Male } & \multicolumn{2}{|c|}{ Female } \\
\hline & $\begin{array}{c}15-19 \\
(n=182)\end{array}$ & $\begin{array}{c}20-24 \\
(n=266)\end{array}$ & $\begin{array}{c}15-19 \\
(n=171)\end{array}$ & $\begin{array}{c}20-24 \\
(n=167)\end{array}$ \\
\hline \multicolumn{5}{|l|}{ Socio-demographics } \\
\hline \multicolumn{5}{|l|}{ Religion } \\
\hline Muslim & 61.9 & 64.7 & 59.6 & 59.1 \\
\hline Christian & 36.5 & 34.7 & 38.9 & 39.2 \\
\hline Others & 1.7 & 0.6 & 1.6 & 1.8 \\
\hline Currently in school & 67.4 & 41.5 & 58.6 & 19.3 \\
\hline \multicolumn{5}{|l|}{ Economic status } \\
\hline Earn income & 32.4 & 54.9 & 24.9 & 68.9 \\
\hline \multicolumn{5}{|l|}{ Sexual behaviour } \\
\hline Ever used condom & 48.6 & 49.4 & 32.6 & 39.4 \\
\hline$>2$ Partners last 30 days & 44.6 & 49.5 & 14.7 & 10.0 \\
\hline $\begin{array}{l}\text { Did not use condom at last } \\
\text { sex }\end{array}$ & 61.7 & 62.1 & 64.8 & 70.1 \\
\hline \multicolumn{5}{|l|}{ Self efficacy } \\
\hline Refuse sex without condom & 57.4 & 55.5 & 38.9 & 45.2 \\
\hline Use condom properly & 78.5 & 79.7 & 52.6 & 62.8 \\
\hline Use condom always & 48.6 & 49.4 & 32.6 & 39.4 \\
\hline Confident to buy condom & 83.3 & 76.2 & 31.8 & 46.4 \\
\hline \multicolumn{5}{|l|}{ Condom Opinions } \\
\hline Reduces HIV risk & 86.1 & 80.5 & 90.1 & 89.2 \\
\hline $\begin{array}{l}\text { Girls using them care about } \\
\text { self }\end{array}$ & 60.6 & 58.4 & 65.8 & 66.9 \\
\hline They are affordable & 92.0 & 89.3 & 74.1 & 78.5 \\
\hline $\begin{array}{l}\text { Not needed in serious } \\
\text { relationships }\end{array}$ & 59.6 & 63.7 & 65.8 & 72.1 \\
\hline \multicolumn{5}{|l|}{ Indicate lack of trust } \\
\hline Encourage promiscuity & 44.1 & 39.1 & 33.3 & 24.7 \\
\hline \multirow[t]{2}{*}{ Reduces sexual pleasure } & 65.4 & 71.0 & 49.2 & 44.2 \\
\hline & 73.3 & 73.4 & 57.8 & 60.2 \\
\hline \multicolumn{5}{|l|}{$\begin{array}{l}\text { Perceived Social Support for } \\
\text { condoms }\end{array}$} \\
\hline Parents support use & 9.6 & 11.4 & 10.6 & 13.9 \\
\hline Friends support use & 57.2 & 50.3 & 60.1 & 64.2 \\
\hline Community support use & 41.9 & 39.9 & 76.3 & 71.6 \\
\hline
\end{tabular}

Generally, boys demonstrated higher condom-related self-efficacy than girls. More than half of boys and less than half of girls reported being confident to 'refuse sex without condoms', 'use a condom properly', 'use a condom always' or 'purchase a condom'. Younger girls demonstrated the least efficacy with regard to condom use. Knowledge about condoms as a protective measure was high among all respondents, with $80 \%$ reporting that condoms reduce the risk of HIV infection (not shown). Similarly, the majority of respondents reported that condoms are affordable, the lowest proportion being among girls aged $15-19$ years (74.1\%). Male respondents make up the majority of those reporting that condoms reduce sexual pleasure $(73 \%)$, while girls, especially older ones reported that condoms are not needed in serious relationships $(65.8 \%$ and $72.1 \%)$. In addition, while the majority of boys reported that condoms encourage young people to be promiscuous, less than half of girls shared this opinion. Overall, the majority of all respondents reported that condoms do not indicate a lack of trust in one's partner.

The social environment is an important determinant of the sexual behaviour or young people. Thus, perceptions of support from significant others in the community can considerably influence their actions. The proportion of respondents who perceived support for condom use from parents, peers and other adults in the community was higher among girls than boys across age groups. Such perceptions, especially from peers and other adults in the community, may encourage girls to be more enthusiastic and able to use condoms since they are more affected by the negative consequences of sexual activity.

\section{Determinants of condom use}

Tables 2 and 3 show logistic regression models calculated to predict adolescents who are more likely to use condom. Separate models were fitted for males and females to control for the effects of gender.

Among females, table 2 shows that younger girls aged 15-19, are more likely to use condoms than older girls. The effect was significant in models 1 to 3 . Risk perceptions (model 2) and believing that condoms reduce sexual pleasure (model 3) were significantly less likely to determine use. Perceived social support for condom use from peers, parents and non-parental figures in the community was associated with higher odds of condom use, although the effect was only significant when peers and other adults were concerned. Generally girls who are more likely to use condoms are those who believe that serious relationships do not need condoms, that condoms do not reduce sexual pleasure and those who feel that significant others around them support condom use.

Among boys, table 3 shows that age was significantly associated with higher odds of condom use. Younger males, aged 15-19 were one and a half times more likely to use condoms than older males. Those who earn an income were also more likely to use condoms, though the effect was not significant. Unlike females, risk perception was associated with higher odds of condom use among males and the effect was significant. Those who were worried about getting infected with AIDS were two and a half times more likely to use condoms. Believing that condom use is not embarrassing and that condoms are easy to use was significantly associated with higher odds of condom use among boys. Boys who agreed that condoms were easy to use were three times more likely to use condoms compared with those who disagreed. Although perception of social support for condom use was associated with a higher likelihood of use, the effect was not significant among male respondents. Generally among males, age, risk perception, and some beliefs about condoms predict higher odds of use. 
Table 2: Odds ratios (standard error) of likely condom use among Females

\begin{tabular}{|c|c|c|c|c|}
\hline \multirow[b]{2}{*}{ Variables } & \multicolumn{4}{|c|}{ Models } \\
\hline & 1 & 2 & 3 & 4 \\
\hline \multicolumn{5}{|l|}{ Background Variables } \\
\hline $15-19$ & $1.68(.236)^{*}$ & $1.59(.238)^{*}$ & $1.60(.246)^{*}$ & $1.48(.256)$ \\
\hline $20-24(r)$ & - & - & - & - \\
\hline \multicolumn{5}{|l|}{ Religion } \\
\hline $\begin{array}{l}\text { Islam } \\
\text { Christian(r) }\end{array}$ & $\begin{array}{r}0.85(.195) \\
-\end{array}$ & $0.89(.197)$ & $\begin{array}{r}0.98(.204) \\
-\end{array}$ & $\begin{array}{r}0.95(.214) \\
-\end{array}$ \\
\hline \multicolumn{5}{|l|}{ Currently in school? } \\
\hline No (r) & $\begin{array}{r}1.10(.203) \\
-\end{array}$ & $\begin{array}{r}1.10(.231) \\
-\end{array}$ & $\begin{array}{r}1.14(.204) \\
-\end{array}$ & $\begin{array}{r}1.10(.200) \\
-\end{array}$ \\
\hline \multicolumn{5}{|l|}{ Earn income } \\
\hline Yes & $1.43(.256)$ & $1.35(.259)$ & $1.32(.267)$ & $1.37(.284)$ \\
\hline No(r) & - & - & - & - \\
\hline \multicolumn{5}{|l|}{ Risk Perceptions } \\
\hline AIDS? & & $0.67(.210)^{*}$ & $0.58(.227)^{* *}$ & $0.64(245)$ \\
\hline $\begin{array}{l}\text { Yes } \\
\text { No(r) }\end{array}$ & & - & - & - \\
\hline \multicolumn{5}{|l|}{ Condom beliefs and } \\
\hline $\begin{array}{l}\text { self-efficacy } \\
\text { Condom reduces risk of } \\
\text { STI/HIV? } \\
\text { Yes }\end{array}$ & & & $\begin{array}{r}0.85(.333) \\
-\end{array}$ & $\begin{array}{r}0.911(.345) \\
-\end{array}$ \\
\hline $\begin{array}{l}\text { Don't know (r) } \\
\text { Serious relationships } \\
\text { need no condoms }\end{array}$ & & & $\begin{array}{r}1.45(.222) \\
-\end{array}$ & $1.79(.238)^{*}$ \\
\hline $\begin{array}{l}\text { Agree } \\
\text { Disagree (r) }\end{array}$ & & & $\begin{array}{r}1.36(.210) \\
-\end{array}$ & $\begin{array}{r}1.65(.222) \\
-\end{array}$ \\
\hline $\begin{array}{l}\text { Condom use is not } \\
\text { embarrassing } \\
\text { Agree } \\
\text { Disagree (r) }\end{array}$ & & & $\begin{array}{r}0.54(.484) \\
-\end{array}$ & $\begin{array}{r}1.00(.513) \\
-\end{array}$ \\
\hline $\begin{array}{l}\text { Condoms are easy to } \\
\text { use } \\
\text { Agree } \\
\text { Disagree (r) }\end{array}$ & & & $0.47(.215)^{* * *}$ & $0.37(.230)^{* * *}$ \\
\hline $\begin{array}{l}\text { Condoms reduce sexual } \\
\text { pleasure } \\
\text { Agree } \\
\text { Disagree (r) }\end{array}$ & & & & $0.41(.283)^{* * *}$ \\
\hline $\begin{array}{l}\text { Perceived social support } \\
\text { for condoms from }\end{array}$ & & & & $0.46(.534)$ \\
\hline $\begin{array}{l}\text { Friends } \\
\text { No }\end{array}$ & & & & - \\
\hline Yes (r) & & & & $0.59(.223)^{* *}$ \\
\hline $\begin{array}{l}\text { Parents } \\
\text { No } \\
\text { Yes (r) }\end{array}$ & & & & \\
\hline $\begin{array}{l}\text { Adults in the } \\
\text { community } \\
\text { No } \\
\text { Yes (r) }\end{array}$ & & & & \\
\hline
\end{tabular}

Levels of significance: ${ }^{*} \mathbf{p}<0.05 \quad * * p<0.01 \quad{ }^{* * *} p<0.001 \quad \mathrm{r}$ (reference category)

In table 4, respondents were required to indicate from a list of options why they did not use condoms the last time they had sexual intercourse. Among boys, not wanting to appear promiscuous was mentioned by $55 \%$ of younger boys and by $61 \%$ of older boys. Other reasons were desire to maximize sexual pleasure (50\% vs $49 \%$ ) and 'being caught in the heat of the moment' (38\% vs $35 \%$ ), indicating the sporadic and unplanned nature of intercourse. A considerable proportion also mentioned being 'embarrassed to buy condoms (34\% vs $28 \%)$ ' and partner refusal (28\% vs $24 \%)$. Among younger and older girls 'not wanting to appear promiscuous' (67\%), 'embarrassed to buy condoms' (62\% vs 54\%) and partner refusal $(39 \%$ vs $35 \%)$ were mentioned as reasons for not using condoms at the last sexual intercourse. Condom availability did not appear to constitute a reason for nonuse across sex and age categories.
Table 5 further explored differences in attitudes to condom use among users and non-users. In this case, participants responded to a structured list of common beliefs/opinions about condoms. The responses obtained provide further insights into condom use behaviour. Among males, $62 \%$ of users believed that a girl who carries condoms care about herself. The corresponding proportion among non-users was 55\%. In terms of condom availability, almost all those who are users believed condoms are easily available and affordable ( $93 \%$ ) compared with only $26 \%$ of non-users. Ninety-four percent of non-users believed condoms promote promiscuity, compared with $26 \%$ of users. Among females, $71 \%$ of non-users believed that carrying condoms indicate a plan to have sex compared with only $33 \%$ of those who are users. While $91 \%$ of girls who are non-users believe condoms reduce sexual pleasure, only $28 \%$ of users shared this opinion.

Table 3. Odds ratios (standard error) of likely Levels of significance: ${ }^{*} \mathrm{p}<0.05, \quad * * \mathrm{P}<0.01$

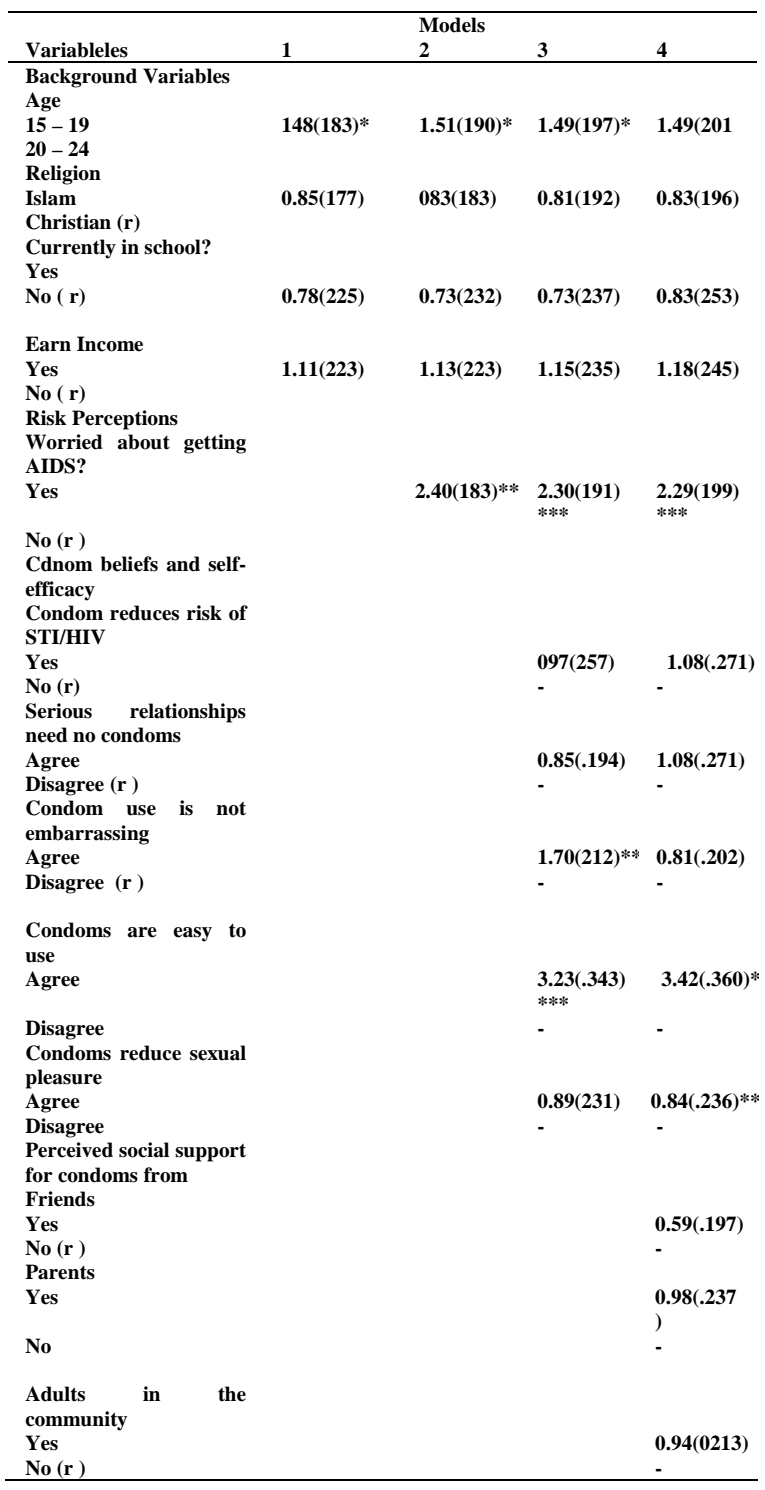


Table 4: Reasons for not using condoms at last intercourse

\begin{tabular}{|c|c|c|c|c|}
\hline & \multicolumn{2}{|l|}{ Male } & \multicolumn{2}{|l|}{ Female } \\
\hline & $15-19$ & $20-24$ & $15-19$ & $20-24$ \\
\hline Condoms break/unreliable & 14.0 & 15.0 & 14.0 & 14.0 \\
\hline Maximize sexual pleasure & 50.0 & 49.0 & 35.0 & 24.0 \\
\hline Partner refused & 28.0 & 24.0 & 39.0 & 35.0 \\
\hline Used other method & 10.0 & 8.0 & 15.0 & 8.0 \\
\hline Did not discuss condoms & 14.0 & 21.0 & 29.0 & 19.0 \\
\hline Embarrassed to buy one & 34.0 & 28.0 & 62.0 & 54.0 \\
\hline No place to buy one & 1.0 & 3.0 & - & 2.0 \\
\hline $\begin{array}{l}\text { Caught in the heat of the } \\
\text { moment }\end{array}$ & 38.0 & 35.0 & 19.0 & 18.0 \\
\hline $\begin{array}{l}\text { Did not want to appear } \\
\text { promiscuous. }\end{array}$ & 55.0 & 61.0 & 67.0 & 67.0 \\
\hline Total No & 71 & 119 & 66 & 100 \\
\hline
\end{tabular}

Table 5: Beliefs about condoms

\begin{tabular}{|c|c|c|c|c|}
\hline & \multicolumn{2}{|c|}{ Male } & \multicolumn{2}{|c|}{ Female } \\
\hline & $\begin{array}{l}\text { Likely } \\
\text { Users }\end{array}$ & $\begin{array}{l}\text { Non- } \\
\text { users }\end{array}$ & $\begin{array}{r}\text { Likely } \\
\text { Users }\end{array}$ & $\begin{array}{l}\text { Non- } \\
\text { users }\end{array}$ \\
\hline $\begin{array}{l}\text { Girl who carry condom care } \\
\text { about self }\end{array}$ & 61.8 & 54.8 & 78.6 & 53.2 \\
\hline $\begin{array}{l}\text { Carrying condoms means plan } \\
\text { to have sex }\end{array}$ & 36.8 & 75.3 & 33.4 & 70.7 \\
\hline $\begin{array}{l}\text { Condoms are easily available } \\
\text { and affordable }\end{array}$ & 93.1 & 26.0 & 87.3 & 40.0 \\
\hline $\begin{array}{l}\text { Girls who request condoms } \\
\text { loose respect }\end{array}$ & 54.6 & 53.4 & 67.5 & 57.1 \\
\hline $\begin{array}{l}\text { Requesting condoms is a sign } \\
\text { of mistrust }\end{array}$ & 57.3 & 62.5 & 85.8 & 52.0 \\
\hline $\begin{array}{l}\text { Condoms } \\
\text { promiscuity }\end{array}$ & 28.0 & 82.2 & 81.8 & 61.5 \\
\hline Reduce sexual pleasure & 57.2 & 93.1 & 28.4 & 91.7 \\
\hline $\begin{array}{l}\text { Condoms can slip off inside } \\
\text { the woman }\end{array}$ & 49.5 & 80.8 & 47.9 & 82.0 \\
\hline $\begin{array}{l}\text { Condoms are used for sex } \\
\text { during }\end{array}$ & 70.6 & 46.6 & 60.2 & 51.2 \\
\hline Menstruation Total N & 138 & 245 & 83 & 124 \\
\hline
\end{tabular}

\section{Conclusions}

Since 2004, the UNAIDS AIDS epidemic updates have reported that adolescents, especially girls, account for an increasing number of those who are newly infected with the HIV virus. The report highlights the fact that many young people who are sexually active are unable to adopt measures to protect themselves against infection. Apart from abstinence, condoms offer an effective protection against STIs/HIV; as such they have been promoted as a strategy for slowing the spread of infections. In view of the escalating rates of infections among sexually active young people, it is important to reexamine the factors that facilitate or impede condom use behaviour.

This study highlights important issues that should be the focus of condom promotion interventions among socio-economically disadvantaged adolescents whose vulnerability to HIV is heightened given the connection between poverty and HIV/AIDS (50, 51). This study showed that condom use behaviour of adolescent slum dwellers is similar to what has been reported among the general population of adolescents in Nigeria $(1,52,53$,). That is, a large proportion of adolescents are sexually active, with multiple partners without any form of protection. Whereas knowledge of condoms and its protective effects was high, previous studies (58-61) have established that knowledge alone does not change behaviour.

Earlier studies $(19,55,57,62)$ reported that condom use among adolescents is influenced by self-efficacy and self-esteem. Findings in this study show that while this may be true for boys, it may not apply in the case of girls. The likelihood of using condoms is increased among girls who perceive social support from friends and nonparental figures in the community. This highlights the need to adopt different strategies toward increasing condom use among boys and girls living in slum communities. While further research is needed to establish if this is the case among girls in higher socioeconomic groups, programs and policies aiming to increase the number of adolescents who use condoms should seek to increase community support for adolescents' condom use in slum settings. For such programs and policies to be effective adult gatekeepers of young people's sexual health need to acknowledge the connection between unprotected sex and HIV infection and be willing to facilitate the adoption of protective measures by those who are sexually active. Similarly, young people need to be aware that their previous sexual history and those of their partners can increase their susceptibility for acquiring infection. Since increased risk perception is associated with increased likelihood of condom use, programs should aim at dispelling the myths that underestimate vulnerability to HIV.

In the context of HIV/AIDS facilitating social support for sexually active girls is important toward empowering them to adopt protective behaviour $(5,34$, $40)$. Some studies $(63,64)$ focused on the possible influences of peers and parents on HIV and condom use among adolescents. Van Landingham (64) shows the potential for peer influence and especially peer group norms on whether individuals condone the use of condoms or not. This body of literature shows that the relative connectedness of adolescents to significant others may be important protective factors, and thus operate as suppressors of risk. Although, studies $(65,66)$ have documented limited communication about sexuality issues between adults and young people, the results of the study highlight the importance of encouraging communication about sexual health between adults and young people as this is likely to have an effect on perceptions of social support and therefore encourage the adoption of protective behaviour among young people who are socio-economically disadvantaged. Other studies [for example Magnani and others (67)] however, showed a weak association between adolescent's sexual risk taking behaviour and their connection to parents. Nevertheless, it is worthwhile to further explore the effects of these factors among all categories of adolescents in order to design appropriate and targeted interventions.

Clearly, these findings suggest that knowledge about condoms is not the obstacle. Perhaps, availability is also not an obstacle since condoms are freely distributed by many existing non-governmental organizations to the populace. Therefore, the low prevalence of use may be the result of many factors, including underestimation of 
risks and the constraints in the social environment. Individuals may not be able to protect themselves even if they want to because of socio-cultural constraints or because of economic circumstances or inequalities that characterize the sexual relations between men and women. Young women are particularly at risk in this regard as the combined effects of gender inequality and poverty may considerably dis-empower them, thereby increasing their vulnerability.

Understanding the dynamics of condom use behaviour among young people requires a better understanding of the dynamics of their sexual relationships and the context within which condom use is (or is not) negotiated. It is necessary however to reevaluate the strategies with which programs that aim to improve sexual and reproductive health of adolescents are delivered. Almost all adolescent reproductive health programs implemented in Nigeria and in the study area in particular have been delivered within a school based or clinic based framework with the result that adult gatekeepers in the community and a large proportion of adolescents who do not have access to these settings are excluded from participating in these interventions. Implementing interventions via family or community frameworks may be more useful in reaching adolescents in disadvantaged settings.

\section{References}

1. Amazigo U, Silva N, Kaufman J, Obikeze D. Sexual activity and Contraceptive knowledge and use among In-School Adolescents in Nigeria. Int Fam Plan Persp 1997, 23(1): 28-33

2. Smith DJ. These Girls Today Na War-o: Premarital Sexuality and Modern Identity in Southeastern Nigeria. Africa Today, 2000, 47 3/4; 99-120

3. Joint United Nations Programme on AIDS (UNAIDS): Nigeria. Epidemiological Fact Sheets, 2002 Update. Available: http://www.unaids.org/html/pub/Publications/Factsheets01/Nigeria EN pdf. http://www.unaids.org/html/pub/Publications/Factsheets01/Nigeria EN_pdf.

4. Arowojolu AO, Ilesanmi AO, Roberts OA, Okunlola MA. Sexuality, contraceptive Choice and AIDS Awareness among Nigerian Undergraduates. Afr J of Repr Health 2002, 6(2): 60-70

5. Slap GB, Lot L, Huang B, Daniyam CA, Zink TM. Succop PA. Sexua behaviour of adolescents in Nigeria: cross sectional survey of secondary school students. British Med J 2003; 4, 326(7379):15.

6. The Allan Guttmacher Institute. In their own right: Addressing the sexual The Allan Guttmacher Institute. In their own right: Addressing

7. National Population Commission/ORC Macro: Nigerian Demographic and Health Survey 2004

8. Federal Ministry of Health Nigeria. National HIV Sero-prevalence Sentinel Survey Technical Report. Federal Ministry of Health, Abuja, Nigeria 2003

9. Brieger WR, Delano GE, Lane C et al. The West African Youth Initiative Project: Outcome of a Reproductive Health Education Program. Journal of Adolescent Health, 2001; 29(6):436-446

10. Green EC.: Rethinking AIDS Prevention: Learning from Successes in Developing Countries. Praeger Publishers, 2003

11. Odutolu $\mathrm{O}$. Convergence of behaviour models for AIDS risk reduction in sub-Saharan Africa. International Journal of Health Planning and Management 2005; 20(3):239-252

12. Brockerhoff M, Brennan E. "The Poverty of Cities in Developing Regions." Population and Development Review, 1998; 24(1): 75-114.

13. Zulu EM, Dodoo FN, Chika-Ezeh A. Sexual risk-taking in the slums of Nairobi, Kenya, 1993-8. Population Studies. 2002; 56(3):311-23.

14. Gardner R, Blackburn RD, Upadhyay UD. Closing the condom gap. Baltimore: Johns Hopkins University School of Public Health, Population Information Program. Population Reports Series H. No 9, 1999

15. World Bank. Confronting AIDS: Public priorities in a global epidemic. New York. Oxford University Press, 1997.

16. Trussell J, Vaughan B. Contraceptive failure, method-related discontinuation and resumption of use: results from the 1995 National Survey of Family Growth. Family Planning Perspectives, 1999; 31(2): 64-72 \&93

17. Cates W. Jr. The NIH Condom report: the glass is $\mathbf{9 0} \%$ full. Family Planning Perspectives 2001; 33(5):231-233

18. Holmes KK, Levine R, Weaver M. "Effectiveness of condoms in preventing sexually transmitted infections.” Bulletin of the World Health Organization 2004; 82:454-461.

19. Peltzer K, Oladimeji $\mathrm{Y}$. Some factors in condom use among first year Nigerian University students and black and white South Africans. Psychology Report, 2004; 94(2): 583-6

20. Nigerian Demographic and Health Survey 2003. National Population Commission, Abuja, Nigeria 2004.

21. Smith DJ. Imagining HIV/AIDS: morality and perceptions of personal risk in Nigeria. Medical Anthropology 2003a; 22(4): 343-72.
22. Smith DJ. Premarital sex, procreation, and HIV risk in Nigeria. Studies in Family Planning 2003b; 35(4):223-35.

23. Onoh HE Mbah AU, Chukwuka JC, Ikeme AC. HIVAIDS awareness and sexual practices among undergraduates in Enugu, Nigeria. Nigeria Postgraduate Medical Journal 2004; 11 (2) 121-125

24. Olaseha IO, Ajuwon AJ, Onyejekwe OC. Reproductive health knowledge and use of contraceptives among adolescent mothers in a sub-urban community of Oyo State, Nigeria. African Journal of Medicine and Medical Science 2004; 33(2):139-43

25. Shelton JD, Johnston B. Condom gap in Africa: Evidence from donor agencies and key informants. British Medical Journal 2001; 323 (7305): 138139

26. Allen A. Sex change Uganda v condoms. The New Republic Online, 2002. http://www.thenewrepublic.com/docprint.mhtml?i=20020527\&s=allen052702

27. Heasrt N, Chen S. Condom Promotion for AIDS Prevention in the Developing World: Is it working? Studies in Family Planning 2004; 35(1): 39-47

28. Mann JM, Nzilambi N, Piot P. et al. HIV infection and associated risk factors in female prostitutes in Kinshasa, Zaire. AIDS 1998; 2(4):249-254

29. Darrow WW. Condom use and use effectiveness in high risk populations. Sexually Transmitted Diseases 1989; 16(3):157-160

30. Taha TE, Canner JK, Chiphangwi JD et. al. Reported condom use is not associated with incidence of sexually transmitted diseases in Malawi. AIDS 1996; 10(2): 207-212

31. Ahmed S, Lutalo T, Wawer M. et. al. HIV incidence and sexually transmitted disease prevalence associated with condom use: A population study in Rakai, Uganda. AIDS 2001; 15(16): 2,171-2,179

32. Wilson D, Lavelle S. Psychosocial predictors of intended condom use among Zimbabwean adolescents. Health Education Research 1992; 7(1): 55-69

33. Akande A. AIDS-related belief and behaviors of students: Evidence from two countries (Zimbabwe and Nigeria). International Journal of Adolescence and Youth 1994; 4(3): 285-303

34. Estrin D. In Ghana, young men's condom use is linked to lack of barriers, perceived susceptibility to HIV infection. International Family Planning Perspectives 1999; 25(2): 106-107

35. MacPhail C, Campbell C. 'I think Condoms are good, but aai, I hate those things": Condom Use Among Adolescents and Young People in a South African Township. Social Science and Medicine. 2001; 52(1): 1613-1627

36. Ezumah NN. Gender issues in the prevention and control of STIs and HIV/AIDS: Lessons from Awka and Agulu, Anambra State, Nigeria. African Journal of Reproductive Health 2003; 7(2):89-99.

37. Bongaarts J, Cohen B. (eds.) Adolescent reproductive behaviour in the developing world. Studies in Family Planning 1998; 29(2)

38. Barker GK, Rich S. "Influences on Adolescent Sexuality in Nigeria and Kenya: Findings from Recent Focus-Group Discussions." Studies in Family Planning, 1992; 23(3): 199-210

39. Meekers D, Klein M, Foyet L. Patterns of risk behaviour and condom use among youth in Younde and Douala, Cameroon. AIDS and Behaviour 2003; 7(4) 413-420

40. Gage AJ. "Sexual activity and contraceptive use: the components of the decision making process.” Studies in Family Planning 1998; 29(2):154-66.

41. Turner CL, Ku S, Rogers L, Duberstein L, Pleck J. Sonenstein FL. Adolescent sexual behaviour, drug use and violence. Increased reporting with computer survey technology. Science 1998; 280(5,365):867-873

42. Van de Wigert J, Padian N, Shiboshi S, Turner C. Is audio-compuer-assisted self-interviewing a feasible method of surveying in Zimbabwe? International Journal of Epidemiology 2000; 29(5):885-890

43. Mensch B, Hewett $P$, Erulkar A. The reporting of sensitive behaviour among adolescents: A methodological experiment in Kenya. Paper presented at the $24^{\text {th }}$ General Conference of the International Union for the Scientific Study of Population, Salvador, Brazil, 18-24 August, 2001.

44. Dare OO, Clelland JG. Reliability and validity of survey data on sexual behaviour. Health Transition Review (Suppl) 1994:93-110

45. Nunn AJ, Wagner HU, Okongo JM, Malamba SS, Kengeya-Kayondo JF and Mulder DW. HIV-1 infection in a Ugandan town on the trans-African highway: prevalence and risk factors. International Journal of STDS and AIDS, 1996; 7 (2):123-130.

46. Quigley M, Munguti K, Grosskurth $H$ et al. Sexual behaviour patterns and other risk factors for HIV infection in rural Tanzania: a case-control study. AIDS, 1997; 11:237-248

47. Weir SS, Roody RE, Zekeng L, Ryan KA, Wong EL. Measuring condom use: asking "do you or don't you" isn't enough. AIDS Educ Prev. 1998a; 10(4):293-302

48. Weir SS, Fox LJ. Bayardo AD. Guerrero GE. Hassig SE. Measuring condom use among sex workers in the Dominican Republic. International Journal of STD \& AIDS 1998b; 9(4):223-226(4)

49. Crosby RA. Condom use as a dependent variable: measurement issue relevant to HIV prevention programs. AIDS Educ Prev. 1998; 10(6):548-57

50. Schoepf B. 1996: Health, Gender relations and Poverty in the AIDS Era: In K. Shelodn (ed): Courtyards, Markets, City Streets: Urban Women in Africa. Westview Press, Boulder: CO. 1996

51. Whiteside A. AIDS and Poverty: The Links. AIDS Analysis Africa 2001; 12(2):1-5

52. Van Rossem R, Meekers D, Akinyemi Z. Consistent condom use with different types of partners: Evidence from tow Nigerian surveys. AIDS Education and Prevention 2001; 13(3): 252-267

53. Umaru US, Adekunle AO, Bakare RA. Pattern of condom use among commercial sex workers in Ibadan, Nigeria. African Journal of Medicine and Medical Science 2001; 30(4): 285-90.

54. Adih W, Alexander C. Determinants of condom use to prevent HIV infection among youth in Ghana. Journal of Adolescent Health 1999; 24(1): 63-72

55. Kapiga SH. Lugalla JLP. Sexual behaviour patterns and condom use in Tanzania: results from the 1996 Demographic and Health Survey. AIDS Care 2002; 14(4): 455-469 
56. Peltzer K. Factors affecting condom use among senor secondary school pupils in South Africa. Central African Journal of Medicine 2000; 46(11): 302-308

57. Meekers D, Klein M. Determinants of Condom use among Young people in Urban Cameroon. Studies in Family Planning 2002; 33(4) 335-346

58. Farmer P, Kim J. Anthropology, accountability and the prevention of AIDS. Journal of Sex Research 1991; 28: 203-221

59. Sobo EJ. Choosing unsafe sex, AIDS-risk denial among disadvantaged women. Pennsylvania. University of Philadelphia, 1995.

60. King R. Sexual behavioral change for HIV: Where have theories taken us? Geneva: UNAIDS, 1999.

61. Macintyre K, Rutenberg N, Brown L, Karim A. Understanding perceptions of HIV risk among Adolescents in Kwa-Zulu-Natal. AIDS Behaviour 2004; 8(3)
62. Macintyre K, Brown L, Sosler S. It is not what you know, but who you knew: AIDS mortality and behaviour change in Africa. AIDS Prevention and Education, 2001; 13: 160-174.

63. Edem CU, Harvey SM. Use of health belief model to predict condom use among university students in Nigeria. International Journal of Community Health Education, 1995; 15:3-14.

64. Van Landingham MJ, Supraset S. Grandjean N. Sittitrai W. Two views of risky sexual practices among northern Thai males: The health belief model and the theory of reasoned action. Journal of Health and Social Behaviour, 1995; 36(2):195-212.

65. Aggleton P. Campbell C. Working with young people: Towards an agenda for sexual health. Sex and Relationship Therapy, 2000; 15(3): 283-296

66. Perrino T. Gonzallez-Soldevilla A. Pantin H. Szapocznik J. The role of Perrino T. Gonzallez-Soldevilla A. Pantin H. Szapocznik J. The role of
families in adolescent HIV prevention: A review. Clinical Child and Family Psychological Review 2000; 3(2): 81-96Magnani RJ. Karim A. Weiss L. Bond K. Lemba M. Morgan G. Reproductive health risk and protective factors among youth in Lusaka, Zambia. Journal of Adolescent Research, 2001; 30 76-86. 